\title{
Compliance of postoperative instructions following the surgical extraction of impacted lower third molars: A randomized clinical trial
}

\author{
Joaquín Alvira-González ${ }^{1}$, Cosme Gay-Escoda ${ }^{2}$
}

\begin{abstract}
${ }^{1}$ DDS, MS. Master degree program in Oral Surgery and Implantology. Faculty of Dentistry - University of Barcelona Spain
${ }^{2}$ MD, DDS, MS, PhD. Chairman and professor of Oral and Maxillofacial Surgery, Director of the Master Degree Program in Oral Surgery and Implantology, Faculty of Dentistry, University of Barcelona, Coordinator \& Researcher of the "Fundació Institut d'Investigació Biomedica de Bellvitge" (IDIBELL Institute), L'Hospitalet de Llobregat, and Oral and Maxillofacial Surgery Departament, Hospital Quirón Teknon, Barcelona, Spain
\end{abstract}

Correspondence:

Teknon Medical Center

C/Vilana 12

08022 Barcelona, Spain

cgay@ub.edu

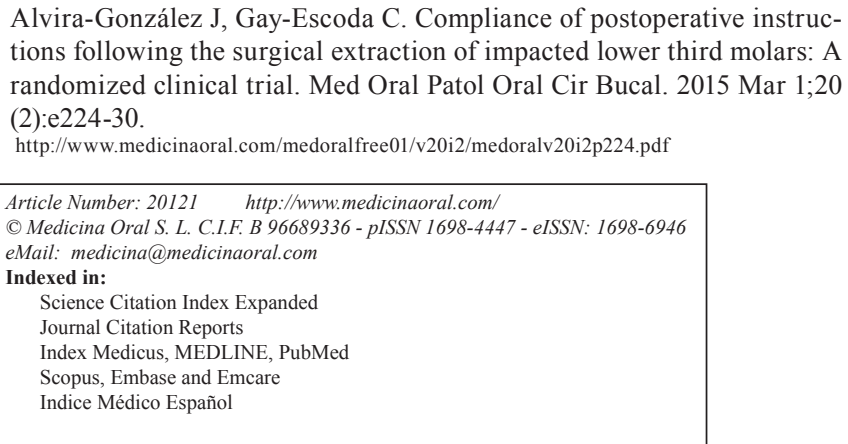

\begin{abstract}
Objectives: The understanding and adherence to postoperative care instructions are factors that influence the recuperation process after any surgical procedure. The aim of this study was to determine the percentage of patients who strictly follow the postoperative instructions after the extraction of an impacted lower third molar in relation to sociocultural level, preoperative anxiety scores and how postoperative information is provided to the patient. Study Design: Patients were randomly assigned to one of three different test groups according to how the postoperative instructions were presented: verbal, written and a group that received additional information. Before surgery, patients were required to complete the Corah Dental Anxiety Scale and personal information (age, gender and educational level) was also collected. $P<0.05$ was considered significant. Patients were surveyed a week after surgery regarding their adherence to postoperative instructions.

Results: 84 patients ( 45 women and 39 men with an average of $28.23 \pm 7.41$ years) completed the study. There were no statistically significant differences regarding adherence of postoperative care instructions depending on the manner of instruction presentation, preoperative anxiety level and sociocultural level ( $p>0.05)$. Quitting smoking or drinking of alcoholic/carbonated beverages were the main influential factors for the lack of adherence to postoperative care instructions during the week after surgery.

Conclusions: Presentation of postoperative instructions, preoperative anxiety scores and sociocultural level do not appear to be key factors that promote the adherence to postoperative instructions.
\end{abstract}

Key words: Compliance, postoperative instructions, treatment, third molar. 


\section{Introduction}

Lower third molar extraction is the most common surgical procedure in Oral Surgery and it appears well documented in literature. Several authors have described different factors that may influence the degree of difficulty as well as the impact of this procedure on the quality of life of patients during the postoperative care (1-4). However, the postoperative period is also influenced by the understanding of the patient and the subsequent implementation of the guidelines presented by the professional in order to minimize morbidity, complications and to improve the quality of life of the patient.

The main elements that could interfere with the understanding of postoperative care instructions are how they are presented by the professional (verbally and/or written) and the sociocultural level of the patient (5-7). However, there are no references in the literature that consider how these two concepts may influence the adherence to postoperative instructions or its possible correlation to the level of preoperative anxiety that is common in any surgical procedure. All these factors could be obstacles to the proper adherence to postoperative instruction for the patient during the recovery period.

The main objective of this study was to determine the percentage of patients who strictly follow the postoperative instructions after the extraction of the impacted lower third molar, taking into account how the information is presented to the patient, the sociocultural level and level of preoperative anxiety. Secondly, to identify the main points of non-compliance and the reason for failure. The hypothesis is that patients with a lower level of preoperative anxiety, higher sociocultural level and who are given both full verbal and written information about the postoperative course will strictly follow postoperative instructions.

\section{Material and Methods}

A total of 90 patients with an impacted lower third molar that required surgical removal for the first time were selected. The patients chosen for the study were healthy (ASA I) or had mild systemic disease without functional limitation (ASA II). All patients underwent surgical extraction of impacted lower third molar. Patients ex- cluded from the study were those who could not attend the scheduled appointments, had a limited intelligence quotient, some psychological disorder or mental condition and had difficulties in language comprehension. The exclusion criteria ensured that only the patients that had no difficulties in understanding and following through with the study were selected.

The study was designed according to CONSORT guidelines for randomized clinical trials and was approved by the Research Ethics Committee (CEIC) of the Dental Clinic of the University of Barcelona, Spain (8). All patients were treated in the Hospital Odontològic de Bellvitge, University of Barcelona, Spain. The incorporation of each subject in the study was decided before knowing the assigned group. Patients were randomly assigned to one of the following three study groups (sequence generated by www.randomization.com):

- Verbal: postoperative instructions were given verbally together with a prescription sheet of the postoperative medication.

-Written: the usual postoperative instructions were given verbally and written, as well as the postoperative medication.

- Additional information: instructions and postoperative medication were given both verbally and written, and additional written information about the postoperative period was also provided (Tables 1,2).

Patients were interviewed about their adherence to the instructions one week after the surgery, at the time of suture removal. They were requested about the compliment of the instructions given, number of days that medication and recommendations were followed and the reason of abandon (Table 3).

Before surgery, patients completed the Corah Dental Anxiety Scale (9) and data about age, gender and educational level (Basic, High School / Vocational Training, University) was also collected. Postoperative instructions were given by one resident previously instructed to provide similar instructions according to the study group to which the patient belonged. All surgical interventions were carried out by second year residents of the Master of Oral Surgery and Implantology (Bar-

Table 1. Postoperative information provided to written and additional information groups after the surgical extraction of third molars.

\begin{tabular}{|l|}
\hline $\begin{array}{l}\text { POSTOPERATIVE INFORMATION AFTER THE EXTRACTION } \\
\text { OF A THIRD MOLAR }\end{array}$ \\
\hline 1. Keep pressing a folded gauze for 30 minutes after extraction. \\
\hline 2. Avoid rinsing with any liquid for the first 24 hours. \\
\hline 3. Do not spit. \\
\hline 4. Take a soft or semi-liquid diet at low or warm temperature. \\
\hline $\begin{array}{l}\text { 5. Apply ice wrapped in a cloth on the outside of the face where the } \\
\text { extraction has been performed. }\end{array}$ \\
\hline 6. Maintain proper oral hygiene. \\
\hline $\begin{array}{l}\text { 7. Avoid smoking during the postoperative period (7 days after surgery) } \\
\text { and do not consume alcoholic/soft drinks during the week after. }\end{array}$ \\
\hline
\end{tabular}


Table 2. Information provided to the group of additional information only.

\begin{tabular}{l} 
ADDITIONAL INFORMATION TO POSTOPERATIVE INSTRUCTIONS \\
\hline 1. Haemorrhage (bleeding): For several hours, saliva can be slightly bloody. This should be swallowed, never spit. \\
Do not perform work or exercise that requires significant efforts. \\
In case of heavy bleeding, remove blood using a gauze, place another gauze on the bleeding area (not cottonwood), \\
and press it with your teeth for 30 minutes (repeat $2-3$ times). If the bleeding continues, contact your surgeon. \\
\hline 2. Oedema (swelling): facial oedema usually occurs several hours after surgery, increasing even during the first $2-3$ \\
postoperative days. Apply cold (ice pack) during the first 24 hours to help reduce inflammation and discomfort and \\
use two pillows to sleep, with the head slightly elevated. Avoid efforts for the first days. Sometimes it can be \\
associated with an haematoma (bruising) around the area, which usually disappears without treatment, and even with \\
temperature up to $38^{\circ}$. \\
\hline 3. Trismus (difficulty in opening the mouth): Trismus is a common complication after extraction of a wisdom \\
tooth, which gradually disappears with time. It manifests as tightness in the back of the jaw. Do not try to force open \\
and it is important to eat a soft diet the first few days. It is advisable to drink plenty of fluids. Avoid hot and irritating \\
foods. It is advisable to chew on the opposite side. \\
\hline 4. Drugs (medications): Take analgesics, anti-inflammatories and antibiotics according to the recommendations of \\
the surgeon (pay attention to the prescription of each medication and observe the times indicated). \\
\hline It is important not to rinse during the first $24 h$ to avoid dislodging the clot of the wound. One day after surgery and \\
for 15 days rinse with the mouthwash recommended. Brush your teeth as usual, three times daily, and brush the \\
wound using a surgery toothbrush in the affected area. It should be performed after every meal. \\
\hline Postoperative pain can last several days (4-5 days), increasing especially at night and after meals. More dental \\
sensitivity to hot and cold foods in the affected area during the first weeks may appear. \\
Take medication correctly to relieve any discomfort. If the pain is very intense during this time, contact your surgeon. \\
\hline
\end{tabular}

Table 3. Questionnaire to assess the compliance of postoperative instructions following the surgical extraction of impacted lower third molars.

\begin{tabular}{|c|}
\hline $\begin{array}{l}\text { QUESTIONNAIRE TO ASSESS THE COMPLIANCE OF } \\
\text { POSTOPERATIVE INSTRUCTIONS }\end{array}$ \\
\hline $\begin{array}{l}\text { - Did you strictly follow the antibiotic medication prescribed? } \\
\qquad \quad \text { Yes / No......If not, how many days?.......... }\end{array}$ \\
\hline $\begin{array}{l}\text { - Did you strictly follow the NSAID medication prescribed? } \\
0 \quad \text { Yes / No......If not, how many days?.......... }\end{array}$ \\
\hline $\begin{array}{l}\text { - Did you strictly follow the recommendation of maintaining a soft-temperate diet } \\
\text { for } 24 \text { hours? } \\
\qquad \text { O Yes / No }\end{array}$ \\
\hline $\begin{array}{l}\text { - Did you strictly follow the recommendation of not rinsing or spitting for the first } \\
24 \text { hours after surgery? } \\
\text { o Yes / No }\end{array}$ \\
\hline $\begin{array}{l}\text { - Concerning smokers, ¿Did you strictly follow the recommendation of not smoking } \\
\text { for seven days? } \\
\qquad \quad \text { Yes / No......If not, how many days?........ }\end{array}$ \\
\hline $\begin{array}{l}\text { - Did you strictly follow the recommendation of not drinking alcoholic/carbonated } \\
\text { beverages for the following seven days? } \\
\qquad \quad \text { Yes / No......If not, how many days?........ }\end{array}$ \\
\hline $\begin{array}{l}\text { - Did you strictly follow the recommendation of brushing every day the teeth after } \\
\text { each meal for seven days? } \\
\qquad \quad \text { Yes / No......If not, how many days?........ }\end{array}$ \\
\hline $\begin{array}{l}\text { - Did you strictly follow the recommendation of mouthwashes with clorhexidine } \\
\text { during the week after? } \\
\qquad \quad \text { Yes / No......If not, how many days?........ }\end{array}$ \\
\hline
\end{tabular}

celona University) with a similar surgical technique. Patients did not receive any financial compensation for their participation in the study.

The extraction of the impacted lower third molars was performed under local anaesthesia with articaine $4 \%$ and epinephrine 1:100.000 (Artinibsa, Inibsa, Lliça de Vall, Spain). The surgical area and all materials were steriles. The surgeon lifted a full-thickness flap that was protected by a cheek retractor. Lingual flap retraction with a Freer periostotom was performed only when deemed necessary by the surgeon. A sterile handpiece at low speed $(20,000 \mathrm{rpm})$ and irrigation with sterile distilled water was used to do the ostectomy and the dental sectioning of the third molar, if needed. The wound was sutured with silk 3-0 (Silkam ${ }^{\circledR}$, Braun, Tuttlingen, Germany). The surgical technique was similar to that described by Leonard (10). The following postoperative medication was prescribed: 
- Antibiotic (750 mg Amoxicilin. Clamoxy $l^{\circledR}$-GlaxoSmithKline, Madrid, Spain) orally one tablet every 8 hours for 7 days).

- A NSAID (600mg Ibuprofeno. Espidifen ${ }^{\circledR}$ - Zambon, Barcelona, Spain) orally every 8 hours for 5 days).

- An analgesic (575 mg Metamizol. Nolotil ${ }^{\circledR}$ (Boehringer Ingelheim, Barcelona, Spain) orally, every 8 hours as relief medication).

- Mouthwash (Chlorhexidine Lacer ${ }^{\circledR}$ to $0.12 \%$ (Lacer, Barcelona, Spain), the mouthwash twice daily for 15 days).

All surgeons involved in the study were blinded for which group each patient belonged. Statistical analysis was done using SPSS 15.0 for Windows (SPSS v15.0, SPSS Inc. Chicago, USA, licensed from the University of Barcelona). Demographic data was analysed using Chi-square test and ANOVA test. Chi-square test was used to compare the compliance according to preoperative anxiety level, sociocultural level and how the postoperative instructions were provided. The significance level was set at $p<0.05$.

\section{Results}

Out of the 90 patients who began this study, six were eliminated because they did not attend the follow-up visit one week after surgery (Fig. 1). The results, therefore, are based on 84 patients ( 45 women and 39 men with an average age of $28.23 \pm 7.41$ years) distributed in different test groups according to how postoperative instructions were provided, sociocultural level and the level of preoperative anxiety.

- Type of information (verbal, written and additional)

The degree of adherence to the postoperative guidelines provided by the professional after surgery is shown in table 4. Stopping smoking for the following seven days was one of the guidelines less followed by patients (only $45.6 \%$ of compliance). This was followed by the consumption of alcohol/carbonated beverages (80.9\%). There were no statistically significant differences in the adherence to postoperative instructions regarding how the instructions were provided to the patients (Table 4), without differences between groups in terms of gender

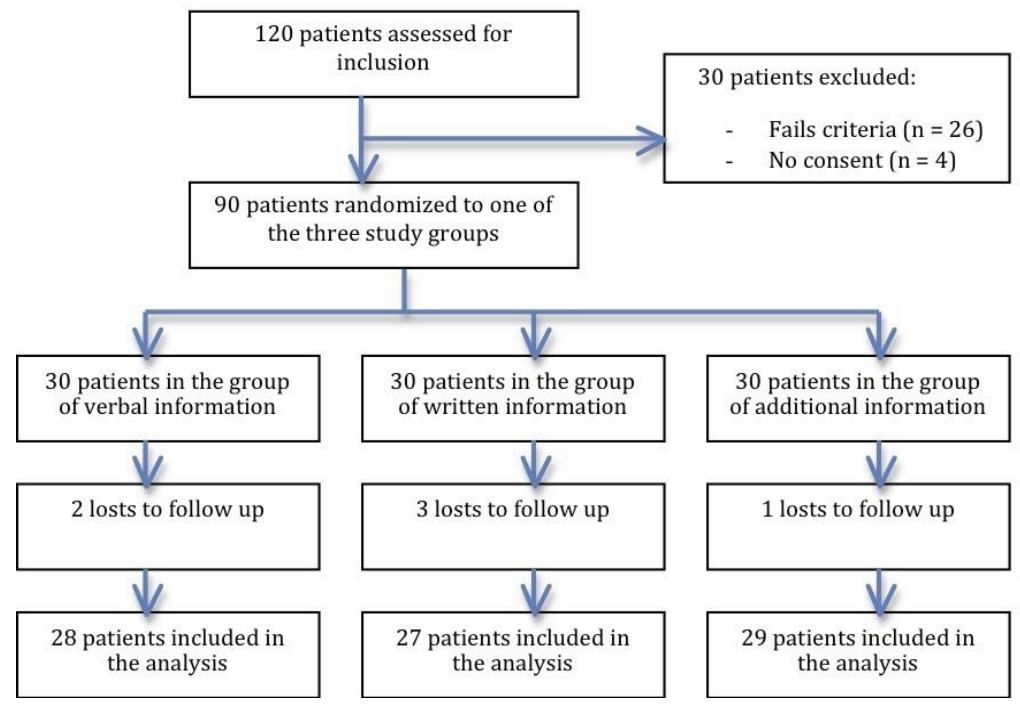

Fig. 1. Flow chart of the participants in the trial.

Table 4. Compliance of postoperative instructions following the surgical extraction of impacted lower third molars.

\begin{tabular}{|c|c|c|c|c|c|c|}
\hline & & $\begin{array}{c}\text { Postoperative } \\
\text { instructions }\end{array}$ & $\begin{array}{c}\text { Preoperative } \\
\text { anxiety }\end{array}$ & $\begin{array}{c}\text { Sociocultural } \\
\text { level }\end{array}$ & Gender & Age $^{\boldsymbol{\alpha}}$ \\
\hline & \% of compliance & $\boldsymbol{P}$ value & $\boldsymbol{P}$ value & $\boldsymbol{P}$ value & P value & $\boldsymbol{P}^{\text {value }}$ \\
\hline Antibiotic & $88.1(\mathrm{n}=74)$ & 0.631 & 0.617 & 0.223 & 0.809 & 0.182 \\
\hline NSAID & $82.1(\mathrm{n}=69)$ & 0.848 & 0.527 & 0.208 & 0.984 & 0.716 \\
\hline Soft diet & $97.6(\mathrm{n}=82)$ & 0.582 & 0.207 & 0.412 & 0.124 & 0.542 \\
\hline Do not rinse (24h) & $91.6(\mathrm{n}=77)$ & 0.993 & 0.145 & 0.206 & 0.064 & 0.542 \\
\hline No smoking* & $45.6(\mathrm{n}=21)$ & 0.234 & 0.879 & 0.706 & 0.264 & 0.281 \\
\hline $\begin{array}{c}\text { No alcoholic/ } \\
\text { carbonated } \\
\text { beverages }\end{array}$ & $80.9(\mathrm{n}=68)$ & 0.746 & 0.192 & 0.687 & 0.005 & 0.943 \\
\hline Teeth brushing & $96.4(\mathrm{n}=81)$ & 0.999 & 0.489 & 0.421 & 0.474 & 0.498 \\
\hline Mouthwash & $98.8(\mathrm{n}=83)$ & 0.383 & 0.702 & 0.156 & 0.349 & 0.797 \\
\hline $\begin{array}{c}\text { Postoperative } \\
\text { course }\end{array}$ & $91.6(\mathrm{n}=77)$ & 0.344 & 0.971 & 0.202 & 0.075 & 0.891 \\
\hline
\end{tabular}

* It takes into account only smokers $(\mathrm{n}=46) .{ }^{\alpha}$ Age groups: $(18-30,31-40,41-50)$. 
$(p=0.627)$, age $(p=0.840)$, sociocultural level $(p=0.790)$ or preoperative anxiety $(p=0.914)$.

\section{- Preoperative Anxiety}

Approximately $74 \%$ of patients reported low or moderate anxiety when facing the first surgical removal of a third molar (Fig. 2). A greater level of anxiety recorded preoperatively did not lead to a greater degree of noncompliance (Table 4), during the seven days after surgery $(p>0.05)$.

- Sociocultural level, gender and age

There were no statistically significant differences in following postoperative instructions according to sociocultural level or age (Table 4 and Fig. 2). In addition, gender is not a factor associated with a greater nonadherence to postoperative instructions, with exception of following the guidelines that prohibit the consumption of alcoholic/carbonated beverages within the seven days after surgery. Approximately $43.5 \%$ of men failed to follow it. Most of the patients (91.6\%) found that the postoperative course experienced was very similar to that explained on the day of surgery, regardless sociocultural level and how the postoperative instructions were provided.
13). However, there are a number of variables that may interfere with the extent and quality of information. For example, how the information is presented, to provide additional information and whether factors such as the level of preoperative anxiety, sociocultural level and age have a role in the adherence and complete understanding of postoperative guidelines.

The non-adherence to postoperative instructions was principally caused by failure of quitting smoking and/ or the consumption of alcoholic/carbonated beverages during the week after surgery, followed by not taking correctly the prescribed medicine (antibiotics and antiinflammatory medication), also observed by Blinder et al. (14). Tobacco represented the main cause of noncompliance, with over $50 \%$ of smokers that continued smoking during the seven days after surgery, regardless of gender, age, level of preoperative anxiety, sociocultural level or how to provide postoperative information. Grossi et al. (15) and Heng et al. (16) identified the smoking habit as a contributing factor of increased postoperative complications and worse postoperative course after a tooth extraction. Consumption of alcohol and carbonated beverages during the postoperative pe-

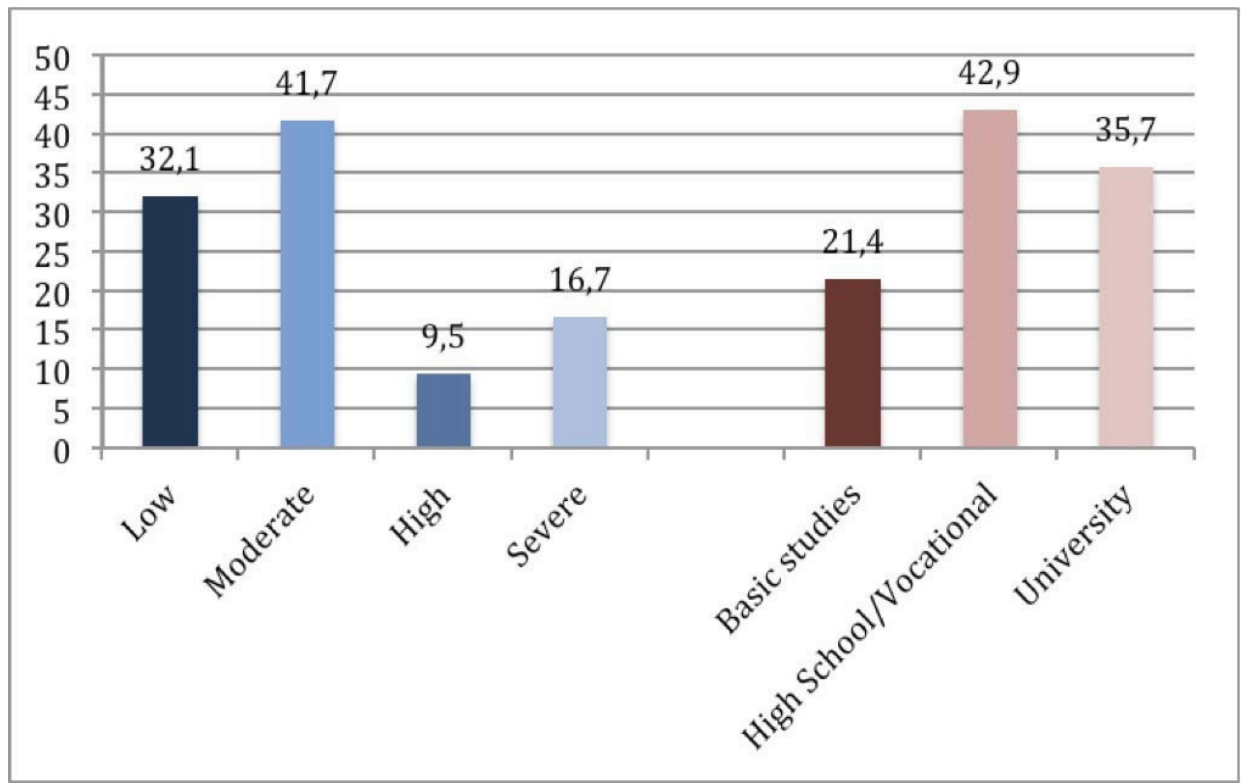

Fig. 2. Distribution of the percentages of patients according to the level of preoperative anxiety (blue) and educational level (red).

\section{Discussion}

The understanding and the subsequent implementation of postoperative guidelines are factors that influence the recovery from any surgical procedure. Some authors state that instructing patients about postoperative care not only reduces postoperative morbidity, but also improves the quality of life during recovery period $(5,11$ - riod was biased by gender, mainly associated with the male gender.

The improper use of antibiotic medication carried out by patients is primarily due to popular beliefs and ignorance about the prescribed medication (17). Pain relief was the main cause of abandonment of anti-inflammatory and antibiotic prescription in our study (40\% 
and $53.3 \%$ respectively), without differences between gender, age, level of preoperative anxiety, sociocultural level or how to provide postoperative information. However, Culbertson et al. (18) pointed out that more than half of the patients in their study preferred both, verbal and written information, about the medication that was prescribed to them. Orero-González et al. (17) found that $32 \%$ of patients self-medicate in the Spanish population, those being oral and respiratory infections the main cause of self-medication. As Blinder et al. (14) advised, it is important to explain properly the need to prescribe and inform the patient of the usefulness of antibiotics because self-medication or a period of inappropriate use of antibiotics can be harmful to the health of the patient.

Vallerand et al. (5) showed that providing postoperative instructions both verbal and written improved compliance of the instructions given by the professional after third molar removal. Houts et al. (19) stated that patients remembered only $14 \%$ of the information when given verbally, compared to $80 \%$ when combined with pictograms, while some authors found that verbal instructions alone were ineffective $(6,14,20)$. In our study, there were not statistical differences in terms of adherence to postoperative guidelines between the groups regarding how the information was presented to the patient. In addition, most patients reported that the postoperative course they experienced did not differ from the information given after the surgical intervention, regardless of the method of presenting the postoperative instructions.

As indicated by Kessels (7), patients forget between $40 \%-80 \%$ of the data given by the professional almost immediately, being the sociocultural level and the age influential factors in comprehension and implementation of postoperative instructions. Besides, there are other closely related variables that must be taken into account and could influence in a suitable patient-professional interaction. Alexander (6) and Kessels (7) emphasize that the degree of illiteracy and ignorance of the language are crucial elements in understanding and compliance of the instructions. There were no statistically significant differences in compliance between different population groups regarding age and educational level in our study. Due to the fact that other variables (illiteracy or ignorance of the language) have not been taken into account in our study group, this could have generated some selection bias in the studied population.

The anxiety generated by any unknown experience is not only a factor related to higher levels of pain perception, but also represents an obstacle for the patients, limiting their attention and compliance of any postoperative instructions given after surgery, especially if they are verbal $(5,7,20-23)$. Besides, as indicated by Brasileiro et al. (24) in their study, patients with previ- ous experience of extractions brought up different questions about the procedure and showed lower anxiety levels compared to patients who have not experienced an extraction. In our study we found that higher levels of preoperative anxiety did not affect the adherence to postoperative instructions after the first surgical extraction of a third molar.

Although several variables could interfere with the adherence to postoperative guidelines, Alexander (6) suggests adapting the instructions to the needs of each patient or case (especially with regard to the limitations of understanding certain terms and ignorance of the language), because a complete and detailed postoperative course and postoperative instructions not only reduces the anxiety that a patient would experience, but also encourages adherence to them indirectly.

\section{Conclusions}

Smoking and the consumption of alcoholic/carbonated beverages during the week after surgery represents the main factors of non-compliance after the extraction of a lower third molar, the latter associated with the male gender. Despite that no differences were found in the compliance of postoperative instructions between the groups regarding the presentation of postoperative instructions, the sociocultural level or the level of preoperative anxiety, it is essential to meet the needs of each patient and provide full details of the postoperative course as well as postoperative instructions.

\section{References}

1. Phillips C, White RP, Shugars DA, Zhou X. Risk factors associated with prolonged recovery and delayed healing after third molar surgery. J Oral Maxillofac Surg. 2003;61:1436-48.

2. Susarla SM, Dodson TB. Estimating third molar extraction difficulty: A comparison of subjective and objective factors. J Oral Maxillofac Surg. 2005;63:427-34.

3. Yuasa H, Kawai T, Sugiura M. Classification of surgical difficulty in extracting impacted third molars. Br J Oral Maxillofac Surg. 2002;40:26-31.

4. Colorado-Bonnin M, Valmaseda-Castellón E, Berini-Aytés L, Gay-Escoda C. Quality of life following lower third molar removal. Int J Oral Maxillofac Surg. 2006;35:343-7.

5. Vallerand WP, Vallerand AH, Heft M. The effects of postoperative preparatory information on the clinical course following third molar extraction. J Oral Maxillofac Surg. 1994;52:1165-70.

6. Alexander RE. Patient understanding of postsurgical instruction forms. Oral Surg Oral Med Oral Pathol Oral Radiol Endod. 1999;87:153-8.

7. Kessels RP. Patients' memory for medical information. J R Soc Med. 2003;96:219-22.

8. Moher D, Hopewell S, Schulz K, Montori V, Gotzsche P, Devereaux P, et al. CONSORT 2010 Explanation and Elaboration: Updated guidelines for reporting parallel group randomised trials. J Clin Epidemiol. 2010;63:1-37.

9. Corah NL. Development of a dental anxiety scale. J Dent Res. 1969;48:596.

10. Leonard MS. Removing third molars: A review for the general practitioner. J Am Dent Assoc. 1992;123:77-8. 
11. Ferrús-Torres E, Valmaseda-Castellón E, Berini-Aytés L, GayEscoda C. Informed consent in oral surgery: The value of written information. J Oral Maxillofac Surg. 2011;69:54-8.

12. Assael LA. Can you hear me now ? Listening to our patients and ourselves. J Oral Maxillofac Surg. 2005;63:425-6.

13. Van Wijk AJ, Buchanan H, Coulson N, Hoogstraten J. Preparatory information for third molar extraction: Does preference for information and behavioural involvement matter?. Patient Educ Couns. 2010;79:94-9.

14. Blinder D, Rotenberg L, Peleg M, Taicher S. Patient compliance to instructions after oral surgical procedures. Int J Oral Maxillofac Surg. 2001;30:216-9.

15. Grossi GB, Maiorana C, Garramone RA, Borgonovo A, Creminelli L, Santoro F. Assessing postoperative discomfort after third molar surgery: a prospective study. J Oral Maxillofac Surg. 2007;65:901-17.

16. Heng CK, Badner VM, Clemens DL, Mercer LT, Mercer DW. The relationship of cigarette smoking to postoperative complications from dental extractions among female inmates. Oral Surg Oral Med Oral Pathol Oral Radiol Endod. 2007;104:757-62.

17. Orero-González A, Ripoll-Lozano MA, González-Núñez J. Analysis of automedication with antibiotics in Spain. Enferm Infecc Microbiol Clin. 1998;16:328-33.

18. Culbertson VL, Arthur TG, Rhodes PJ, Rhodes RS. Consumer preferences for verbal and written medication information. Drug Intell Clin Pharm. 1988;22:390-6.

19. Houts PS, Bachrach R, Witmer JT, Tringali CA, Bucher JA, Localio RA. Using pictographs to enhance recall of spoken medical instructions. Patient Educ Couns.1998;35:83-8.

20. Atchison KA, Black EE, Leathers R, Belin TR, Abrego M, Gironda $\mathrm{MW}$, et al. A qualitative report of patient problems and postoperative instructions. J Oral Maxillofac Surg. 2005;63:449-56.

21. Kim Y, Kim S, Myoung H. Independent predictors of satisfaction in impacted third molar surgery patients. Community Dent Oral Epidemiol. 2010;38:274-86.

22. Lago-Méndez L, Diniz-Freitas M, Senra-Rivera C, SeoanePesqueira G, Gandara-Rey JM, García-García A. Postoperative recovery after removal of a lower third molar: Role of trait and dental anxiety. Oral Surg Oral Med Oral Pathol Oral Radiol Endod. 2009;108:855-60.

23. Van Wijk A, de Jongh A, Lindeboom JA. Anxiety sensitivity as a predictor of anxiety and pain related to third molar removal. J Oral Maxillofac Surg. 2010;68:2723-9.

24. Brasileiro BF, de Braganca RM, Van Sickels JE. An evaluation of patients' knowledge about perioperative information for third molar removal. J Oral Maxillofac Surg. 2012;70:12-8.

\section{Conflict of interest}

The authors declare that they do not have any conflict of interest.

\section{Funding statement}

This study was performed by the "Dental and Maxillofacial Pathology and Therapeutic" research group of the IDIBELL Institute. 